\title{
Users' Social-interaction Needs While Shopping via Online Sales Configurators
}

\author{
Chiara Grosso \\ University of Padua, Department of Management and Engineering, Vicenza, Italy \\ Cipriano Forza \\ University of Padua, Department of Management and Engineering, Vicenza, Italy
}

Received (28.10.2018.); Revised (15.03.2019); Accepted (6.04.2019.)

\begin{abstract}
The growing adoption of social web technologies such as social software (SSW) in online configuration environments has enabled the possibility of supporting configurator users in interacting digitally with real people while they are shopping for customized products. Previous research has identified that online sales configurators (OSCs) are currently connected to SSW with different modalities to provide configurator users with a variety of options to digitally interact with real people. Enriching the configuration environment with social-interaction tools has engendered the phenomenon of socialproduct customization. Recent studies considered the social product-customization by investigating the impact that community feedback and social comparisons has on configurator user. However, the OSCs users' need to interact with different referents during their configuration process, and whether the SSWOSCs connections respond to this need are still unsearched. To address this gap, the present study explores (a) whether users experience the need to interact with different referents while shopping via OSCs and (b) which interaction modalities users are looking for. By considering 943 configuration experiences from 189 users of 378 OSCs for various consumer goods, the present study finds that the need for social interaction by OSC users is highly relevant. Moreover, OSC users perceive the need to interact with different referents during different stages of the configuration process, and, depending on the referent with whom they wish to interact, they are interested in different interaction modalities in terms of how and where those interactions take place. These findings imply that mass customizers may leverage their customers' need to interact with real people while shopping online via OSCs in order to better engage their actual and potential customers.
\end{abstract}

Key words: Online sales configurator, social web, social software, user experience, collaborative virtual environment, mass-customization toolkits, electronic commerce

\section{INTRODUCTION}

The process of selling customized products is increasingly occurring via online sales configurators (OSCs). OSCs are mass-customization (MC) toolkits designed to support potential customers in choosing the product configuration that best suits their needs from a company's web product offerings [1-3]. However, selling through the web is challenging not only because it is a new sales method for many companies but also because e-commerce is undergoing a constant evolution driven by the adoption of a variety of social web technologies [4].

Social web technologies enhance connections among individuals [5] and groups of web users. The implementation of social web applications such as social software (SSW) within e-commerce platforms has led customers to experience new online social interactions (e.g. reviewing and rating products and services and participating in collaborative shopping experiences) $[6$,
7]. The interactive nature of these technologies not only connects digital customers across the web but also changes the expectations that customers have of companies [8].

A digital customer refers to a customer or potential customer who uses digital devices to buy online (e.g. via a smartphone, tablet, or PC) or engage with brands, other customers, or members of their circle by using online channels (e.g. social media (SM), social network platforms) [8, 9]. From the company's perspective, building digital customer experiences refers to building customer engagement by taking advantage of social web technologies (e.g. SSW), tools, and channels (e.g. SM) to better understand and serve its customers [10].

As reported by Kane et al. [11], a high percentage of companies $(87 \%)$ are adopting SM for business purposes. SM include online communication media and social networking sites incorporating SSW that allow 
users to create personal profiles and lists of contacts, add or invite other users, and share content in different formats (e.g. pictures, videos, music, and URLs) [12]. The adoption of SM is having a revolutionary impact across and outside of companies [13-15]. For instance, SM are fostering new collaboration opportunities between companies and other parties (e.g. suppliers, vendors, and customers) [16, 17], and are changing relationships among consumers themselves [7].

Digital customers are no longer isolated, unlike the first generation of e-commerce website users; on the contrary, they are hyper-connected and can influence other customers' choices [7, 18, 19]. Customers' negative comments about products, companies, or buying experiences remain visible online and can negatively influence other customers' zero moments of truth, the moment when a potential customer decide to buy online [20]. The adoption of SSW implemented into e-commerce websites can be advantageous for companies in terms of deriving customer insights or cutting costs by providing customer care via social technologies, but it can also be risky if the investment in those technologies is not properly managed [21-23].

Companies that adopt MC strategy (i.e. companies that offer customized products without a substantial trade-off in cost, delivery, and quality [24-26]) have recently joined SSW applications to their OSCs to aid users during the configuration process $[27,28]$. Complementing a configurator with SSW makes the configurator a highly interactive digital shopping environment that supports users with social interactions similar to those that a customer can experience in a retail environment [28]. The interactive nature of SSW connected to OSCs has created a socially-enriched configuration environment that is also known as a socially-enriched MC system [23] or a social-product customization system [29].

Despite the widespread adoption of SSW for business purposes, only a few studies have examined the emerging phenomenon of connecting SSW to the OSC environment. Previous studies have investigated the social interaction between peers (e.g. configurator users, professional designers) during the configuration process. In particular, research has investigated the impact of social comparisons between peers of equal or higher expertise on consumers' evaluations of the products that they had configured [29, 30], the role of OSC peer communities [18, 31], and the influence of the feedback provided by peers during the initial self-design stage on the uniqueness of the final configuration solution chosen by users [23]. However, no studies have yet addressed the users' need to interact with real people when shopping for customizable products via OSCs.

Studying users' needs regarding social interaction while shopping for configurable products can help mass customizers provide end users with proactive support via OSCs. More specifically, this investigation can help mass customizers to design interaction modalities matching those that users look for during their configuration processes. Regarding this specific aspect, previous research has focused on the connection between configurators and SSW [27, 28], but no studies have yet investigated the effectiveness of these technology investments, specifically in terms of whether those connections respond to the configurator users' need to socially interact.

The present paper aims at reducing this gap (a) by exploring the extent to which OSC users need to interact with real people during the configuration process and (b) by exploring the interaction characteristics that these users are looking for. The findings related to these two aspects are compared with the social interaction options enabled by the current OSC-SSW connection modalities.

\section{THEORETICAL BACKGROUND}

\subsection{Customers' interaction behaviors while shopping offline and online}

\subsubsection{The customer-socialization process}

The literature on customer research attributes high importance to the customer-socialization process for customer decision making while shopping [32-34]. Customer socialization refers to the process by which individual customers learn skills, knowledge, and behaviors from others through communication, which then assists them in functioning as customers in the marketplace [34-36]. According to customersocialization theory, communication among customers affects their cognitive, affective, and behavioral attitudes [34, 37-41].

Looking in more depth at the socialization process, it is possible to identify three sub-processes; namley: (i) social interaction, (ii) modeling, and (iii) reinforcement. Each sub-process refers to different mechanisms and has a different impact on the specific behavior that an individual adopts to interact with others and participate in a social environment [34, 35, 42].

Social interaction is a sub-process based on direct interactions between two or more actors in social contexts and it can be combined with the subsequent sub-processes of modeling and reinforcement [42].

Modeling is a socialization sub-process that refers to mechanisms of imitation or of mimicking the socialization agents [42]. Socialization agents are those who have a direct or indirect influence on an individual's behavior (e.g. family, friends, peers, the media) [43]. Thus, the social agent's behaviors appear meaningful or desirable to the individual who aims to imitate them. Studies on customer research highlight that the socialization agents who have the most influence on customers' purchase decisions are family, friends, and peers [43, 44]. In addition to the role of the abovementioned socialization agents, it should be noted that the shopping process also includes social interaction between consumers and company representatives (e.g. salespersons).

Reinforcement refers to the socialization sub-process of learning [42]. This sub-process motivates an individual to adopt (or not) some behavior or intention depending on a reward (or punishment) given to him or her by the socialization agent [42, 43]. According to social-learning theory [42], a customer develops consumption behaviors by learning from others (e.g. family, friends, colleagues, persons of equal standing, or other customers) through interaction or by simply observing others' consumption 
behaviors [42, 44]. The learning process enabled by observing others' consumption is defined in the literature as observational learning [42]. Observational learning can positively or negatively affect an individual's decision-making process while shopping. In particular, customers are interested in interacting with socialization agents to simplify their buying tasks, reduce the effort needed to search for information, and decrease the perceived risks of buying [42, 45].

\subsubsection{Social web technologies used to support digital customers}

SSW are web technologies that enhances collaborative and interactive networking between individuals and groups of web users [6]. As stated by previous studies, the communication between peers and members of the same reference groups via SSW applications (e.g. chat boxes, online social networks) enables a form of customer socialization that has a profound impact on customer decision making [19, 46-48].

The socialization process enabled by SSW is possible thanks to SSW's capability of providing communication tools $[1,2]$ that make the social-interaction process easy and convenient (because it usually costs less) via online platforms such as blogs, instant messaging, and social networking sites. For example, in virtual communities, members can interact easily with virtual groups through electronic communication and quickly learn task-related knowledge and skills through their interactions with other members [7, 48].

SSW can support potential customers in learning processes that simultaneously involve the three socialization sub-processes described in the previous subsection: (i) social interaction, (ii) modeling, and (iii) reinforcement.

- Social interaction enabled by SSW: SSW facilitates learning about products and trends by supporting information exchanges among multitudes of friends or peers (socialization agents) who provide various and ample product information and thus enable the quick evaluation of products [49].

- Modeling sub-process enabled by SSW: The ownership of a particular product or service by peers enables the modeling process. SSW can support customers in sharing information about their purchases by reviewing and rating products and services through posting comments or pictures on a blog, forum, or on a social network platform. By doing so, each customer can inform his/her peers and his/her circle about his/her shopping experiences and impact on others' zero moments of truth. This is because the potential customer can "model" his/her shopping by purchasing the same products or avoiding products depending on whether he or she wants to be like his or her peers or not $[48,50]$.

- Reinforcement sub-process enabled by SSW: SSW can support customers in sharing information about their purchases by reviewing and rating products and services through posting comments or pictures on a blog, forum, or on a social network platform. By doing so, pressure from peers and reference groups motivates the potential customer to endorse a product or to purchase it, because once a purchase is shared via SM, it can be a source of rapid social rewards $[48,50]$. Previous research suggests that implementing SSW within company websites supports customers in exchanging information about products or services through participative and socializing experiences $[46,48$, $50,51]$. This happens because in the interactive environment of online social networks, users spontaneously provide and share personal informationthat is, the so-called self-disclosure that occurs when a person discloses personal information about his or her interests, activities, and personal status, as well as photos and videos [52].

SSW can also support digital customers in finding relevant information or products of interest when they face difficulties in searching the vast content on the web [36].

\subsection{Social technologies adopted in the online configurator environment}

\subsubsection{Online sales configurators}

OSCs are knowledge-based software applications that support potential customers or sales people who are interacting with customers online to completely and correctly specify a product solution from within the company's offerings [1-3]. Sales configurators are designed with the purpose of guiding users toward configuration solutions that best fulfill their specific needs [53-56]. In many cases OSCs are implemented with recommendation systems to further facilitate customers in their search for suitable solutions $[51,53,55]$.

Depending on the different capabilities deployed by OSCs, customers can benefit from different kinds of OSC support provided by OSCs during the configuration process [57]. The capabilities of OSCs have been shown to positively influence the benefits related to the configuration experience itself (e.g. hedonic and creative achievement benefits) [57-59] and benefits related to the possession of a configured product (e.g. utilitarian, uniqueness, and self-expressiveness benefits) [2, 60, 61]. Sales of customized products via OSCs, and more generally via configurators, also help mass customizers [62]. Consequently, OSCs, and more generally, product configurators, are also considered as key enablers for MC implementation [63].

Recent studies on the product-configuration process suggest that, for configurators, a promising method of providing feedback, in addition to that one provided by the configurator through the above mentioned capabilities, would be to include a function that allows users to submit their interim design solutions for them to obtain rapid social feedback from other users who are online [64]. This is because OSC users are digital customers and like digital customers who buy online, they are used to gathering information from trustworthy sources such as people who are known to them [47, 49], from reliable sources such as other online users [31], or from experts such as company representatives [65]. The integration of social-collaboration options during product configuration-more specifically, feedback from peersfacilitates the customer's problem-solving process because users can assist each other during the development of the initial idea, during the design process, and by giving each other constructive feedback 
on interim design solutions [18]. One way to integrate into OSCs social-collaboration options is to connect OSCs to SSW.

\subsubsection{Connection modalities between online sales configurators and social software}

SSW has recently been connected to OSCs [27, 28, 57]. Despite the novelty of this phenomenon, an increasing number of OSCs are currently connected to SSW [28]. In just a few years we have witnessed the development not only of the number of OSCs connected to SSW but also the development of the characteristics of these connections.

Recent studies have identified different connection modalities between configurators and SSW [28]. In particular, Grosso et al. [28] identified 8 connection modalities, and since some modalities present with more than one variant, 12 variants in total were identified.

Depending on the characteristics of the SSW connected to the configurator, different social interactions are enabled to support users in interacting digitally with real people while they are configuring their products via an OSC $[27,28]$. Some of the identified modalities support configurator users in sharing their configuration solutions through social network platforms and by interacting with different referents online [27, 28].

Each connection modality supports configurator users and has specific characteristics in terms of (i) when, (ii) where, (iii) with whom, and (iv) during which step of the configuration process social interactions are enabled by each connection modality [28]. A description of each characteristic of the connection between OSCs and SSW is provided in the following paragraphs.

The when characteristic refers to how social interaction can be in terms of timing. Social interaction can be synchronous when the actors involved share the same interaction time (e.g. telephone calls, live chats) or it can be asynchronous when the actors involved do not send/receive messages at the same time (e.g. sending an e-mail, posting on a blog or forum). The when dimension refers to the users' need to interact in a synchronous modality (e.g. real-time interactions such as via live chats) or in an asynchronous modality while configuring a product.

The where characteristic refers to where the interaction can take place, either inside the same environment where the configuration process is taking place [inside] or externally [outside] to the configuration environment (e.g. on another web platform, forum, blog, or web channel).

The with-whom characteristic refers to whom one engages in interactions with such as (a) the users' online contacts, (b) experts from the company, and (c) other configurator users. More precisely, this dimension refers to the users' need to interact with: (a) personal contacts such as individuals whom the user knows and trusts [47], (b) company representatives such as those who have expertise [65], and (c) other configurator users such as individuals of equal standing who have experience shopping via online configurators and with productconfiguration processes [18].

The which-step characteristic refers to the step of the configuration/shopping process during which users need to interact with real people.

To address the different steps of a user's configuration process, we follow the terminology provided by Franke et al. [18] in their study on complementing MC toolkits with user communities. By doing so, the configuration steps are described as follows:

- Initial idea development. In this step (step 1), users start collecting information about the product they are going to configure.

- Intermediate evaluation. In this step (step 2), users evaluate a product configuration that has not been completed, thus it is addressed as a partial product configuration.

- Configuration evaluation. In this step (step 3), users evaluate the product configuration they have chosen, possibly after considering various intermediate configurations, thus it is addressed as a final product configuration.

By making a parallelism between the configuration/shopping process and the step involved in customer decision making during the shopping process [66], we also investigated OSC users' need for social interaction during the post-purchase step. This fourth step (step 4) that is not included in Franke et al.'s work [64] refers to the post-purchasing phase and is a step every customer experiences for every shopping process including shopping for customizable products via OSCs $[66,67]$.

\subsubsection{Positioning of the online social interaction enabled by the online sales configurator-social- software connection}

One important aspect that characterizes the connection modalities between the OSC and SSW concerns their positioning with respect to the configuration environment. Thus, the identified connection modalities are classified into two groups: (a) co-location-based connection modalities and (b) integration-based connection modalities $[15,52]$.

Co-location-based connection modalities are characterized by the simple co-location of the SSW and configurator on the company's website. In this case, even though the SSW is not actually integrated within the configurator, nonetheless the configurator users can take advantage of the SSW during their configuration experiences [28].

Integration-based connection modalities, so called because they are the ones that actually integrate SSW within configurators, thus allow OSC users to access SSW directly from the configurator [28]. To date, only one connection modality enables a connection from the SSW to the OSC: modality 4 (M4, Table 1). This connection modality supports Facebook users when visiting a company's web page that is connected to the company's Facebook page via a simplified version of the product configurator. However, this modality is gradually becoming obsolete [28].

Table 1 is an overview of the 12 connection-modality variants and it provides a brief description of the integration-based and co-located-based connection modalities. Column 1 shows the names of the connection modalities; Column 2 reports a brief description of the 
social interaction enabled by each one; Column 3 reports on where the connections are positioned with respect to the configurator environment.

Table 1. Connections between the online sales configurator and the social software (Source: adapted from Grosso et al. [25])

\begin{tabular}{|c|c|c|}
\hline \multicolumn{3}{|c|}{ Connection modalities and variants } \\
\hline Name & Brief description & Positioning \\
\hline M1 & $\begin{array}{l}\text { Icons on the company's website connect } \\
\text { configurator users to the company's SM } \\
\text { profile(s) }\end{array}$ & Co-located \\
\hline M2.1 & $\begin{array}{l}\text { SM icons enable the user to automatically } \\
\text { publish the configurator link on his/her } \\
\text { social profiles }\end{array}$ & Integrated \\
\hline M2.2 & $\begin{array}{l}\text { SM icons enable the user to automatically } \\
\text { share a complete configuration in the } \\
\text { user's social profile(s) }\end{array}$ & Integrated \\
\hline M2.3 & $\begin{array}{l}\text { SM icons enable the user to automatically } \\
\text { share a partial configuration on the user's } \\
\text { social profile(s) while the configuration is in } \\
\text { process }\end{array}$ & Integrated \\
\hline M3 & $\begin{array}{l}\text { Direct browse/upload into the } \\
\text { configurator's files shared in the user's } \\
\text { SM profile(s) }\end{array}$ & Integrated \\
\hline M4 & $\begin{array}{l}\text { Simplified configurator embedded into the } \\
\text { company's SM profile }\end{array}$ & Integrated \\
\hline M5.1 & $\begin{array}{l}\text { A company blog diary provides the user } \\
\text { with content published by company } \\
\text { representatives (e.g. information about } \\
\text { brands, events, sponsorships) }\end{array}$ & Co-located \\
\hline M5.2 & $\begin{array}{l}\text { A company blog post provides the user with } \\
\text { additional information, not available in the } \\
\text { configurator environment, provided by the } \\
\text { company itself and/or by other blog users }\end{array}$ & Co-located \\
\hline M6 & $\begin{array}{l}\text { A company discussion forum connects the } \\
\text { configurator user to his/her online contacts }\end{array}$ & Co-located \\
\hline M7.1 & $\begin{array}{l}\text { E-mail sends the complete configuration } \\
\text { to the user's online contacts }\end{array}$ & Integrated \\
\hline M7.2 & $\begin{array}{l}\text { The company's e-mail as a company- } \\
\text { customer-service channel }\end{array}$ & Co-located \\
\hline M8 & $\begin{array}{l}\text { Instant message services connect the } \\
\text { configurator user to company } \\
\text { representatives }\end{array}$ & Integrated \\
\hline
\end{tabular}

Co-location-based connection modalities. Co-locationbased modalities are connections between the SSW and online configurators that are enabled outside the configuration environment [28]. These connection modalities support users in interacting differently during the various stages of the configuration and decisionmaking processes. More specifically, the support provided by M.1 and M5.1 focuses on the early stages of the configuration/shopping process (i.e. information searching and evaluating alternatives) while M5.2, M6, and M7.2 support the user during the entire process [28]. Even though these modalities do not allow users to share their configured products, they support users in collecting information that can help them to develop an initial configuration idea and evaluate an intermediate or complete configuration.

Co-location-based connection modalities support users in gathering information and in receiving feedback, mostly from unknown people such as company representatives, social network users (M1), blog users (M5.2), and forum participants (M6) who share an interest in the company's products and who already have experience with similar products. As for M7.2, even though it represents a very basic customer-service mechanism, it allows users to interact with company representatives and is something that users typically expect to find on any commercial website.

Even though co-location-based modalities enable interactions mostly between people who do not know each other, it is worth noting that most of these modalities allow for real-time communication (blog posts, forums, or e-mails). However, there is no guarantee that an interaction will take place when the user needs it because it all depends on the availability of other web users (e.g. blog users or forum participants) [28].

Integration-based connection modalities. Integrationbased connection modalities are connections between the SSW and OSCs that are enabled within the configuration environment [28]. These connections support the user inside the configurator while his or her configuration process is ongoing. Integration-based connections support users in interacting with different referents, both synchronously and asynchronously. Except for M8, all of the integration-based connection modalities support users in interacting with their online contacts, thus allowing them to receive social feedback from already-known people. M4 also allows users to share information both with the user's online personal contacts (i.e. Facebook friends) and company representatives. Except for M3, which does not support social interaction, and M7.1, which supports an e-mail sharing option, social interaction supported by integration-based modalities can be performed in real time. However, since M4 has started to become obsolete, only M8 supports real-time interaction inside the configuration environment. Finally, M2.1, M2.2, and M2.3 only enable real-time interaction outside of the configuration environment, more precisely, on social network platforms that the OSC users have joined. In particular, these modalities enable sharing the configurator's URLs in the OSC user's online social profiles (M2.1), sharing their intermediate designs (M2.2), and sharing the final self-designed products of the configurator users (M2.3) [28].

\subsubsection{The online sales configurator-social-software connection modality during different steps of the configuration/shopping process}

The different connections between OSCs and SSW support users during different steps of the configuration/shopping process, and consequently, during the decision-making process that OSC users face as potential customers while shopping [28]. By following a parallelism between the configuration/shoppingprocess step and the customer decision-making step [66], and then combining these processes with the characteristics of the co-located- and the integrationbased connection modalities, it is possible to find out which modalities support OSC users during each step.

The group of co-located connection modalities (M1, M5.1, M5.2, M6, M7.2) and the group of integrationbased modalities (M2.1, M3, M4, M8) support users during the information-seeking step, which is when customers look for information about the product to be 
configured. This step in the customers' decision-making process corresponds with the initial idea-development step, which is when users look for information on the product to be configured [28].

The groups of co-located connection modalities (M1, M5.2, M6, M7.2) and the group of integration-based modalities (M2.3, M3, M8) support OSC users during the alternative's evaluation step, which is when customers evaluate different products and their characteristics. This step corresponds with the intermediate evaluation step, which is when OSC users evaluate the suitability of their configuration when it is not yet their final choice.

The group of co-located connection modalities (M5.2, M6, M7.2) and the group of integration-based modalities (M2.2, M2.3, M7.1, M8) support users during the purchasing step when customers evaluate if they will or will not buy the selected product. This step corresponds with the final configuration evaluation, when OSC users evaluate the suitability of their final configuration solution before proceeding with their purchase.

During the final post-purchase step when customers evaluate both their purchase experience and the purchased product, only a group of co-located connection modalities (M1, M5.2, M6, M7.1, M8) support OSC users after their purchase of the configured product [28].

\section{METHOD}

Given the early stage of research on OSC users' need for social interaction, we engaged in exploratory research to investigate the characteristics and the extent of this uninvestigated need. We collected empirical evidence (a) to explore whether OSC users experience (or not) the need to interact with real people during their online configuration process and (b) to detect the online social-interaction characteristics OSC users are looking for during their online configuration processes.

In collecting empirical data, we considered the characteristics used by Grosso et al. [28] to describe the current connections between OSCs and SSW. This choice is intended to ease the comparison between the characteristics of the OSC-SSW connection modalities that are currently available and the social interactions that OSC users are looking for during the configuration process.

To analyze the users' need for social interaction, we considered 943 configuration experiences in a sample of 187 potential customers using 378 sales configurators available online. A set of five configurators was assigned to each participant based on his/her preferences for specific product types, thus each OSC set was different for each participant.

After each one of the five configuration experiences, each participant filled in a questionnaire. While $99 \%$ of participants reported data for each one of their five experiences, $1 \%$ of them only took part in four configuration experiences. With the configuration experience as the unit of analysis, we had a data set of 943 observations that we then analyzed with descriptive statistics.

\subsection{Participants' sample description}

With the goal being to analyze a relevant sample of young people, our participants were selected from management engineering students at the authors' university. Previous research has recognized that young people represent the majority of business-to-consumer sales configurator users [1, 60,68 ]. Our sample of 189 participants comprised 129 males and 60 females. The ages of the participants ranged between 22 and 42 years (with an average age of 24 years).

A set of questions was provided to collect data on the participants' online shopping behaviors. Answering the questions was recommended but not mandatory for the participants. Specifically, $79.9 \%$ of the participants were interested in shopping online. In more detail, $47.1 \%$ of the participants were digital customers who made regular purchases on e-commerce websites, while $33 \%$ of them were digital customers who made occasional purchases online (e.g. only in specific product categories). Only $10.6 \%$ of the participants were not interested in online shopping, while the remaining $9 \%$ did not provide any answers. Regarding their interest in sharing their shopping experiences, $74.1 \%$ of the participants had a favorable attitude toward sharing their shopping experiences (online and offline) with someone they already knew (e.g. friends, family, colleagues).

To collect information on the participants' usage of social network platforms (e.g. Facebook, Google+, Twitter, Instagram, Linkedln, YouTube), a set of questions was provided to the participants. Of the participants, $85 \%$ were always connected to their online social networks via their smartphones or tablets. Finally, participants had to select from a set of profile descriptions the ones that matched with their behaviors as online social network users (i.e. regular, moderate, and observer users). Participants could select up to two profiles, and in case there were no matches, they had to provide a brief description of their usage behaviors.

Of the sample, $44 \%$ were moderate users who often logged into their social networks. The most selected profile was the so-called observer user that was chosen by $52 \%$ of the sample. Observers refers to users who log into social networks with the purpose of seeing what other users were doing on social network platforms [69]. They are users who freely view other people's social network profiles to discover interests and information by observing others' activities on social platforms [69]. The remaining $19 \%$ were regular users who logged into SM on a daily basis without always being connected. Only $2 \%$ of the participants did not have an online social network profile.

\subsection{The online sales configurators used for the experiences}

The sample of 378 online sale configurators to be used by the participants to engage in the online configuration experiences was selected from the Cyledge database. This database is the only publicly available list of online sales configurators and it has been used in previous research on OSCs [28].

Among the 1,252 entries in the database, an initial selection was made according to country. A total of 527 configurators were selected from countries where English is the predominant language (i.e. Australia, Canada, India, Ireland, New Zealand, the United 
Kingdom, and the United States). The rationale for choosing configurators from countries where English is the first language is that English is considered the de facto lingua franca [70] for business [71].

The second step of the selection procedure involved stratified probabilistic sampling. Each stratum was identified by a country-industry-product combination. As an industry-classification list, we used the 17 industries proposed in the database (i.e. Accessories, Apparel, Beauty \& Health, Electronics, Food \& Packaging, Footwear, Games \& Music, House \& Garden, Industrial Goods, Kids \& Babies, Motor Vehicles, Office \& Merchandize, Paper \& Books, Pet Supplies, Printing Platforms, Sportswear \& Equipment, and Uncategorized). For each stratum, we randomly chose at least two-thirds of the configurators listed in the database (in the case of fractions, we chose the smallest superior integer). Eventually, the configurators that were no longer active were replaced by active ones, which were randomly chosen from within the same stratum.

\subsection{The questionnaire}

The questionnaire submitted to participants included a set of questions on the need for social interaction they had experienced during each configuration process.

We developed each question as a statement corresponding to the characteristics of the social interaction enabled by SSW currently connected to OSCs [28]. Each statement was measured on a Likerttype scale ranging from 1 to 5 (where 1 corresponds to completely disagree, 2 to disagree, 3 to neither agree nor disagree, 4 to agree, and 5 to completely agree). Due to space constraints in the graphs and tables, in the rest of the article, the term "neutral" substitutes for the third level of agreement (neither agree nor disagree).

The questionnaire included statements about the characteristics of the interaction modalities defined specified in previous research [28] in terms of:

(i) referents with whom the interaction takes place;

(ii) the environment (inside or outside of the configurator) where the interaction takes place;

(iii) when (in real time or not) the interaction takes place, and finally;

(iv) during which step of the configuration/shopping process the interaction takes place.

Accordingly, the questions were structured along these four characteristics, named: (i) with whom, (ii) where, (iii) when, and (iv) which step. The first three mentioned labels-(i), (ii), and (iii) - are the same labels used in previous research with the same purposes and meaning [28]. The last label (iv) has been created to refer to the different steps of the configuration/shopping process used in previous research but without a specific label [28]. In the following, we address to the above-mentioned characteristics-(i), (ii), (iii) and (iv)—as dimensions that characterizes the users' social interaction needs.

All the items used to measure the need for social interaction have been structured in the following way: "During the W step of this shopping experience, I felt the need to interact with $X$, in $Y$ digital environment, in Z way", where: (v) W = "initial idea development" or "intermediate evaluation" or "final evaluation" or "postpurchase";

(vi) $X=$ "users' contacts" or "experts from the company" or "other configurator users";

(vii) $Y=$ "in" or "out" of the configuration environment; and

(viii) $Z$ = "real time" or "non-real time."

This uniform wording of the items allowed for the graphical design of the questionnaire as a table (see Table 2) so that the various options for $W$ and $X$ were in the headings of the columns, $Y$ and $Z$ were placed in the headings of the rows, and the reference item was presented only in the introduction for the table. In this way, the participants did not have to repeatedly read very similar items, they were facilitated in rapidly filling in the questionnaire-

Table 2. Example of a filled-in questionnaire

\begin{tabular}{|c|c|c|c|c|c|c|c|c|c|c|c|c|c|}
\hline \multirow{2}{*}{\multicolumn{2}{|c|}{$\begin{array}{l}\text { QUESTIONNAIRE } \\
\text { EXAMPLE }\end{array}$}} & \multicolumn{4}{|c|}{$x 00=$ My contacts } & \multicolumn{4}{|c|}{$x 00=$ Expers from the company } & \multicolumn{4}{|c|}{$x x=0$ ther configurator uses } \\
\hline & & \multirow{3}{*}{\begin{tabular}{|c|}
$\begin{array}{c}\text { intial } \\
\text { idea } \\
\text { develop }\end{array}$ \\
3 \\
\end{tabular}} & \multirow{3}{*}{$\begin{array}{c}\text { Intem } \\
\text { config }\end{array}$} & \multirow{3}{*}{$\begin{array}{c}\text { Final } \\
\text { config } \\
3\end{array}$} & \multirow{3}{*}{\begin{tabular}{|c|}
$\begin{array}{c}\text { Post- } \\
\text { purt }\end{array}$ \\
5 \\
\end{tabular}} & \multirow{3}{*}{\begin{tabular}{|c|}
$\begin{array}{c}\text { intial } \\
\text { ideo } \\
\text { develop }\end{array}$ \\
4 \\
\end{tabular}} & \multirow{3}{*}{ 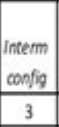 } & \multirow{3}{*}{$\begin{array}{c}\text { Final } \\
\text { config }\end{array}$} & \multirow{3}{*}{$\begin{array}{c}\text { Post } \\
\text { pout } \\
1\end{array}$} & \multirow{3}{*}{$\begin{array}{c}\begin{array}{c}\text { initid } \\
\text { ideo } \\
\text { develos }\end{array} \\
2\end{array}$} & \multirow{3}{*}{$\begin{array}{l}\text { Interm } \\
\text { config } \\
3\end{array}$} & \multirow{3}{*}{$\begin{array}{c}\begin{array}{c}\text { Final } \\
\text { config }\end{array} \\
2\end{array}$} & \multirow{2}{*}{$\begin{array}{l}\text { Poss- } \\
\text { purt }\end{array}$} \\
\hline & & & & & & & & & & & & & \\
\hline \multirow{2}{*}{$\begin{array}{c}\text { No Real } \\
\text { time }\end{array}$} & Intem, config. & & & & & & & & & & & & 1 \\
\hline & Extem. config. & 1 & 2 & 4 & 4 & 1 & 2 & 2 & 1 & 4 & 3 & 4 & 4 \\
\hline \multirow{2}{*}{$\begin{array}{l}\text { Real } \\
\text { time }\end{array}$} & Intern. config. & 4 & 3 & 4 & 4 & 4 & 4 & 1 & 1 & 4 & 1 & 1 & 4 \\
\hline & Extern, config. & 1 & 4 & 5 & 5 & 3 & 3 & 3 & 1 & 4 & 3 & 2 & 4 \\
\hline
\end{tabular}

${ }^{*}$ Question to be answered by participants: During the configuration process, I felt the need to interact with $X X X$

The table contained $48\left(4^{*} 3^{*} 2^{*} 2\right)$ cells. Each cell characterizes the experienced need for social interaction in a certain form and can be identified as $n_{w, x, y, z}^{e}$, where $w$ identifies the configuration/shopping step, $x$ identifies the referent, $y$ identifies where the interaction takes place, $z$ identifies when the interaction evolved, and e is constant for a given experience since it identifies the experience $(e=1 . . E$ where $E=943)$.

\subsection{Data analysis}

Given the explorative and descriptive aims of the present research, descriptive statistics have been adopted to analyze the collected data. According to previous research on product configuration [72], descriptive statistics provide facts and evidence that are necessary to design more articulated researches and analyses.

We based our analysis on a fundamental consideration about the meaning of the data we collected. Participants were not asked whether they preferred to interact in one way or in another way. They were asked how much they perceived the need to socially interact in a certain way (by specifying when, where, with whom, and during which step). Consequently, it could be that a participant felt the need to interact in one way or in more than one of the ways depicted in the questionnaire. The focus of the information is that he/she felt the need to interact. Accordingly, in order to measure how much a given participant felt the need for social interaction during a given configuration experience, we computed the following:

$$
\begin{aligned}
\max _{\mathrm{e}} & \left\{n_{w, x, y, z}^{e}\right\} \\
& \forall \mathrm{e}=1, \ldots, \mathrm{E} .
\end{aligned}
$$


This operationalization allows us to interpret the results without introducing thresholds that can introduce arbitrariness. In this way, to present and interpret our statistical results, we used the original 1-5 Likert scale on which the participants reported the need for interaction that they perceived.

Every analysis was based on a specific formula, even though all the formulas are similar because they are based on the same principle. For example, in relation to Figure 2, the formulas used for detailing the need for social interaction in real time and not in real time (i.e. the when dimension) were, respectively:

$$
\begin{aligned}
\max _{\mathrm{e}} & \left\{n_{w, x, y, z}^{e} \mid z\right\} \\
& \forall \mathrm{e}=1, \ldots, \mathrm{E}, \\
& \forall \mathrm{z} \in\{\text { real time, no real time }\} .
\end{aligned}
$$

Similar formulas were used for each one of the remaining dimensions we adopted to characterize the interactions (i.e. where, which step, and with whom).

Given the importance of the with-whom dimension in the social interaction, we performed a more detailed analysis by exploring how the need for interaction varies by changing the referent of the interaction. In this more finegrained analysis, we used the following formulas for detailing the need for social interaction in real-time and in non-real-time interactions with the user's personal contacts:

$$
\begin{aligned}
\max _{\mathrm{e}}\left\{n_{w, x, y, z}^{e} \mid(x, z)\right\} \\
\forall \mathrm{e}=1, \ldots, \mathrm{E} \\
\forall(\mathrm{w}, \mathrm{x}) \text { where } \\
\quad \mathrm{x} \in\{\text { users' contact, experts from the company, } \\
\quad \text { other configurator users }\} \\
\mathrm{z} \in\{\text { real time, no real time }\}
\end{aligned}
$$

Similar formulas were used for each one of the remaining dimensions that we adopted to characterize the interactions (i.e. where, and which step).

In order to make the reported data more understandable, for the more fine-grained analyses, we collapsed the agreeing values as (4)+(5) and the disagreeing ones as $(1)+(2)$. This aggregation can be seen in Tables 3-6.

\section{RESULTS}

\subsection{Configurator users' need for social interaction: The overall view}

The results for the OSC users' need for social interaction during their shopping experiences on OSCs show that this need was perceived as relevant by participants in almost all their configuration experiences (89\%) (Figure $1)$. It is interesting to note that only in $4 \%$ of the configuration experiences, participants did not experience the need to interact with real people in any form ( $2 \%$ completely disagreed and the other $2 \%$ disagreed), while $8 \%$ of them did not provide a definitive answer regarding whether they perceived this need to be relevant or not.

Notably, Figure 1 implies that most configurator users experienced the need to consult with or be advised by someone instead of facing the configuration experience as individual users who interact only with the configurator. This is an important overall result, since it shows that the need for social interaction is an actual need for almost all configurator users who took part in our study.

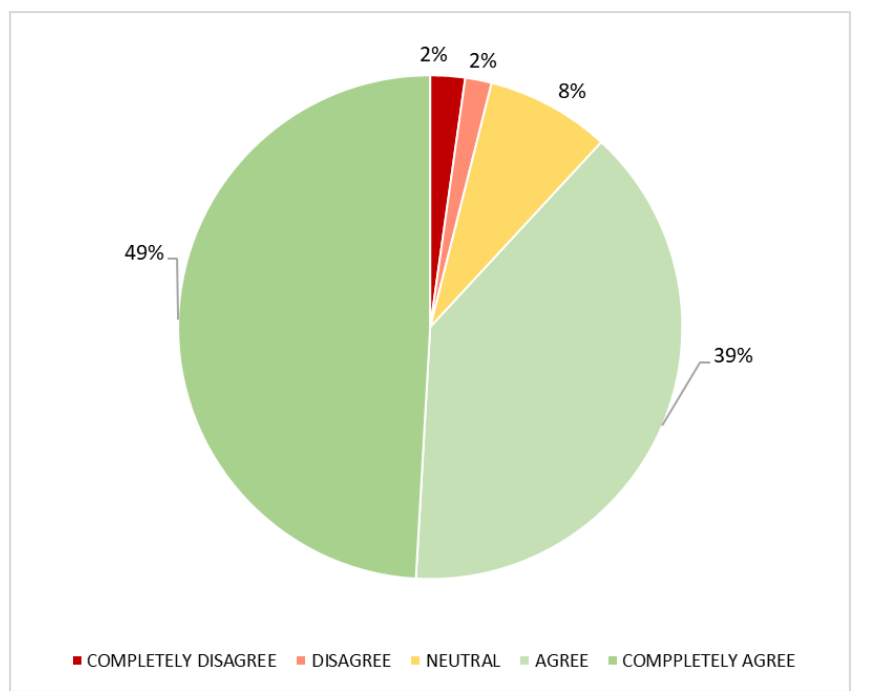

Figure 1. Experienced need for social interaction

\subsection{Configurator users' need for social interaction during the when, where, and which- step dimensions}

The when dimension. One of the characteristics of social interaction is the timing through which it takes place (i.e. synchronous or asynchronous). Figure 2 shows the results for this dimension, where in $83 \%$ of cases, OSC users definitely needed to interact with someone during their shopping experience via OSCs in real time. The need for non-real-time interaction was also highly present, even though it was felt to be relevant in less cases $(68 \%$ of cases instead of $83 \%$ ) and less strongly (participants strongly agreed in only $25 \%$ of cases instead of $45 \%$ ).

These results show that almost all OSC users expect to fulfill their need for social interaction during the configuration experience with interactions performed in real time. Interestingly, non-real-time interaction is not unimportant since most users experienced the need to interact in a non-real-time manner. Moreover, in $64 \%$ of their experiences, participants felt the need to interact both in a real-time and in a non-real-time way.

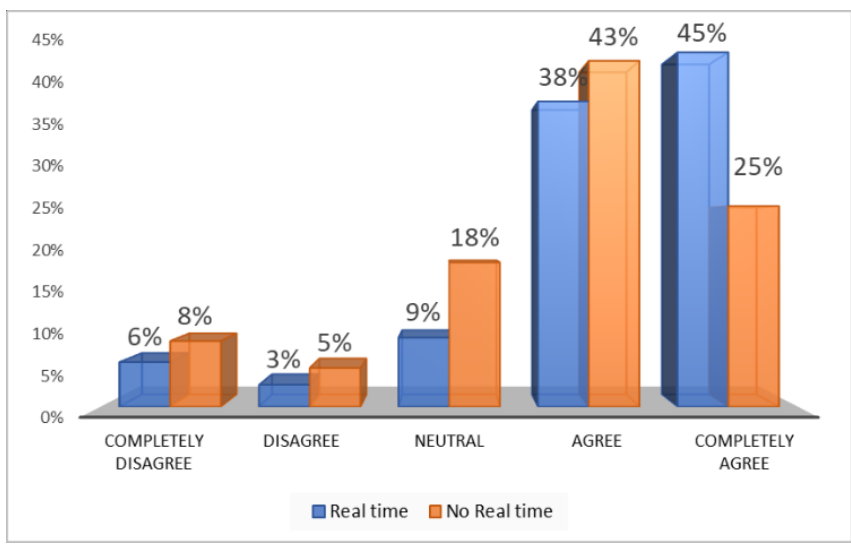

Figure 2. Experienced need for social interaction in real time and in non-real time 
The where dimension. Figure 3 reports the results on where users need to interact; that is, whether this interaction is in the same environment where the configuration takes place (inside the OSC) or in a different one (outside the OSC). The results show that users strongly need to interact socially both inside $(76 \%$ of experiences) and outside (78\% of experiences) of the configuration environment. It is interesting to note that in an extremely low percentage of cases, the users did not perceive an interaction need as relevant either inside $(11 \%)$ or outside of the configuration environment $(8 \%)$.

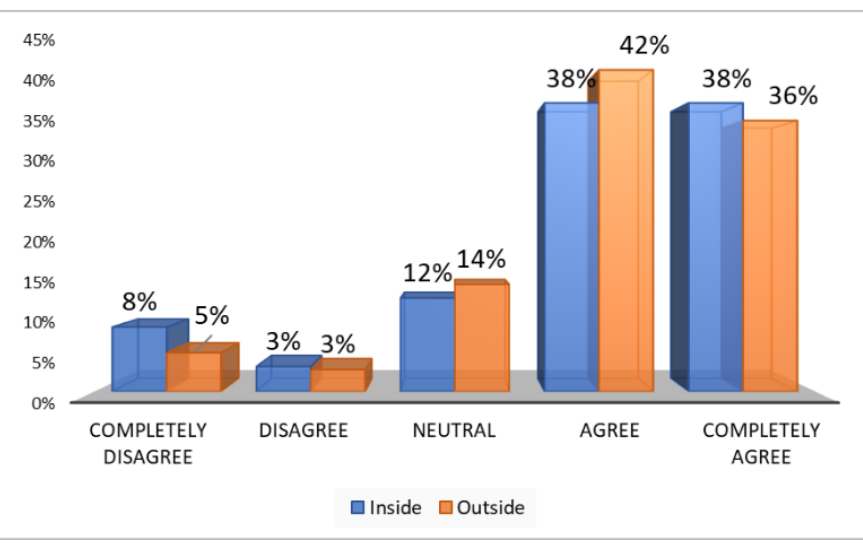

Figure 3. Experienced need for social interaction within and outside the configuration environment

These results suggest that users expect to fulfill their need for social interaction during the configuration process both by staying within the configuration environment and by moving around among environments different from the configuration one to access the social support they need. Therefore, as well being indicated by the $66 \%$ of experiences where users felt the need for social interaction both within and outside the configuration environment, interaction occurring within and outside of the configuration environment are not viewed as alternatives for OSC users.

The which-step dimension. The results in Figure 4 show that the need for social interaction is mostly perceived during the final configuration-evaluation stage $(74 \%$ of cases) when users produce their final configuration solution, most likely after several tries. However, most participants also felt the need for social interaction during the initial stage of idea development (66\% of cases) and during the intermediate stage of configuration evaluation (69\% of cases). In fewer of the experiences (52\%), users felt the need to interact with someone during the postpurchase step.

These results show that OSC users felt the need for social interaction during each step of their configuration process. However, there are slight differences from step to step, and, in particular, the need for social interaction is perceived as more relevant during the final configuration stage when users evaluate their design and are keen to integrate external feedback into their problem-solving process [18].

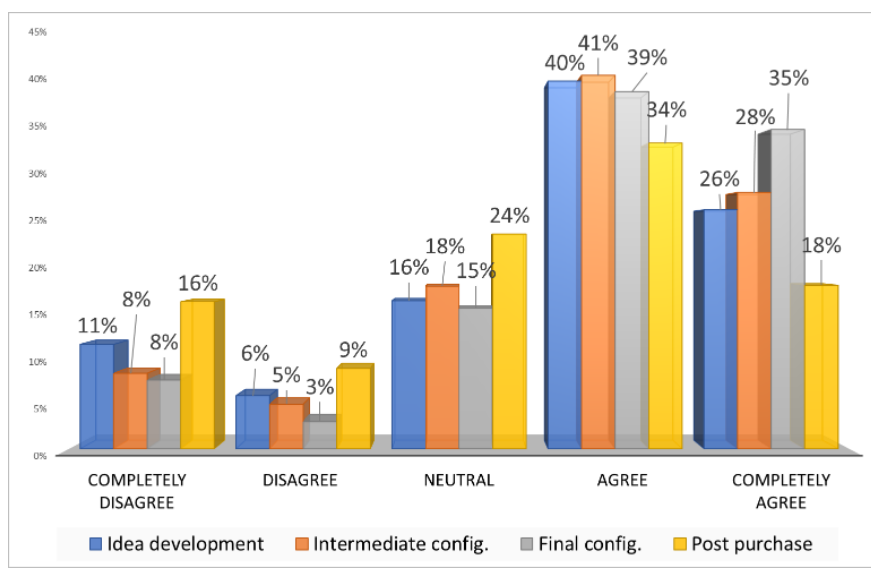

Figure 4. Experienced need for social interaction during the various stages of the configuration process

\subsection{Configurator users' need for social interaction with whom}

The actors involved in social interactions with customers during their shopping decision-making process play a key role in this process. Consequently, in the present subsection, we examine this dimension further, focusing on the users' need to interact with different referents (i.e. the users' contacts, experts from the company, and other OSC users) by analyzing it both alone and in combination with the other previously analyzed dimensions (i.e. where, when, and during which step). The results of the analysis for the combined dimensions are reported in a more aggregated way by providing the sum of the agreement values (completely agree + agree), the sum of the disagreement values (disagree + completely disagree), and the neutral values (neither agree nor disagree) expressed by users.

The with-whom dimension. The results reported in Figure 5 highlight that the need to interact with different actors varies depending on the referent who users need to consult with during their configuration process. This is not surprising, given that different referents provide different kinds of information and support that the users are looking for during their shopping experience via the OSC. The need to interact with the users' contacts, reported in $75 \%$ of cases, underlines the OSC users' demand for consulting trustworthy referents who know their tastes and habits and thus can make recommendations for them in accordance with their preferences.

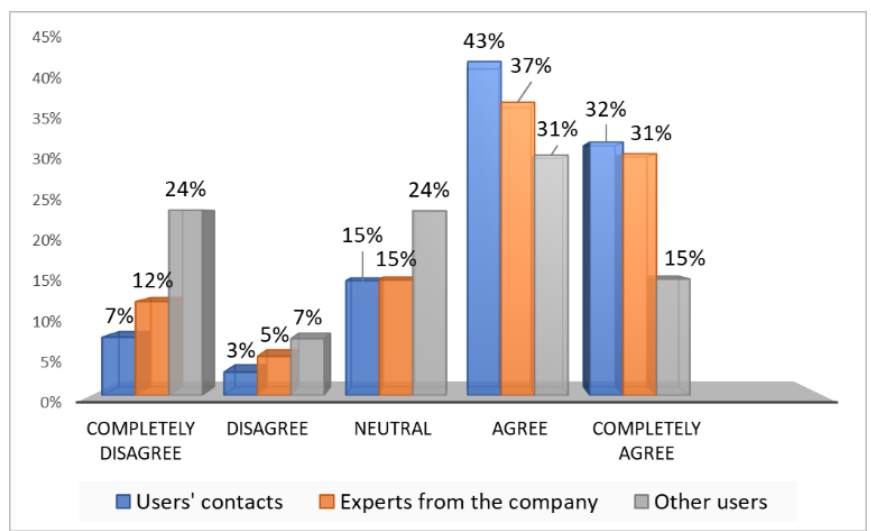

Figure 5. Experienced need for social interaction with different referents 
The need to interact with experts from the company was reported in $68 \%$ of cases. This result underlines the OSC users' demand for consulting expert referents who know the technical details of the product or of the configurator itself.

The need to interact with other configurator users, reported in $46 \%$ of cases, underlines the OSC users' demand for consulting referents who had previously used the configurator or who had bought products that had been personalized on the same configurator. Other users are also considered as referents who can provide information on the reliability of the company, for example, if the company delivered the configured product as scheduled in the order. Despite the information that other configurator users can provide by sharing their experiences, the percentage of experiences in which the OSC user perceived the need to interact with them is the lowest compared to other referents.

Combining the with-whom and when dimensions. Table 3 reports on the results for the users' need to interact in real time with different referents. Interestingly, in most cases, the users needed to interact more frequently in real time with both their contacts (68\%) and with company experts $(62 \%)$. In only one-third of cases $(34 \%)$ did the users experience the need to interact in real time with other OSC users.

Real-time interaction allows users to collect information while the configuration is in process; thus, by interacting in real time, users can apply any changes mentioned by their contacts or by a company expert and then continue with the configuration process. Real-time communication can also reassure users about their choices and allow the exchange of advice, which can help users when particular choices during the configuration process are too complex.

Table 3. Experienced need to interact with different actors in real time or non-real time

\begin{tabular}{|c|c|c|c|c|c|c|}
\hline \multicolumn{7}{|c|}{$\begin{array}{l}\text { During the configuration process, I needed to interact in [real time]/[no- } \\
\text { real time] with ... }\end{array}$} \\
\hline \multirow{2}{*}{$\begin{array}{c}\text { Scale of } \\
\text { Agreement }\end{array}$} & \multicolumn{2}{|c|}{ UXC } & \multicolumn{2}{|c|}{ EXP } & \multicolumn{2}{|c|}{ OCU } \\
\hline & $R T$ & $N R T$ & $R T$ & $N R T$ & $R T$ & $N R T$ \\
\hline Disagreement & $17 \%$ & $27 \%$ & $22 \%$ & $33 \%$ & $43 \%$ & $44 \%$ \\
\hline Neutral & $15 \%$ & $25 \%$ & $16 \%$ & $22 \%$ & $22 \%$ & $23 \%$ \\
\hline Agreement & $68 \%$ & $48 \%$ & $62 \%$ & $46 \%$ & $34 \%$ & $33 \%$ \\
\hline Total & $100 \%$ & $100 \%$ & $100 \%$ & $100 \%$ & $100 \%$ & $100 \%$ \\
\hline \multicolumn{7}{|c|}{$\begin{array}{l}U X C=\text { users' contacts; } E X P=\text { experts from the company; OCU = other } \\
\text { configurator users; } R T=\text { real time; } N R T=\text { non-real time; } \\
\text { Neutral = neither agree nor disagree }\end{array}$} \\
\hline
\end{tabular}

Combining the with-whom and where dimensions. Table 4 reports on the results regarding the users' need to interact in different environments depending on the referents that they can interact with. A noteworthy result is that OSC users look for different places where they can interact digitally with real people depending on the referents that they want to engage with. In $64 \%$ of cases, the users experienced the need to interact with their contacts outside of the configuration environment, for example, on other online platforms or through an online instant messaging service. On the contrary, in $63 \%$ of cases, the users experienced the need to interact with experts from the company inside of the configuration environment, for example, via a live chat.
Table 4. Experienced need to interact with different actors inside or outside of the configurator

During the configuration process, I needed to interact [inside]/[outside] with

\begin{tabular}{|c|c|c|c|c|c|c|}
\hline \multirow{2}{*}{$\begin{array}{c}\text { Scale of } \\
\text { Agreement }\end{array}$} & \multicolumn{2}{|c|}{ UXC } & \multicolumn{2}{|c|}{ EXP } & \multicolumn{2}{|c|}{ OCU } \\
\hline & In & Out & $\ln$ & Out & $\ln$ & Out \\
\hline Disagreement & $33 \%$ & $17 \%$ & $22 \%$ & $34 \%$ & $45 \%$ & $42 \%$ \\
\hline Neutral & $18 \%$ & $19 \%$ & $15 \%$ & $20 \%$ & $23 \%$ & $22 \%$ \\
\hline Agreement & $49 \%$ & $64 \%$ & $63 \%$ & $46 \%$ & $32 \%$ & $35 \%$ \\
\hline Total & $100 \%$ & $100 \%$ & $100 \%$ & $100 \%$ & $100 \%$ & $100 \%$ \\
\hline $\begin{array}{l}\text { UXC = users'co } \\
\text { configurator use } \\
\text { outside of the co } \\
\text { disagree }\end{array}$ & acts; E & $=\exp$ & ts from & compa & $y ; O C U$ & $\begin{array}{l}\text { other } \\
\text { ut }= \\
\text { nor }\end{array}$ \\
\hline
\end{tabular}

As regards the third type of referent (i.e. other OSC users), it was found that the participants felt the need to interact with them similarly within and outside of the configurator. In fact, Table 4 shows that the participants looked for an interaction with other OSC users inside the OSC $32 \%$ of the time, and outside the OSC in $35 \%$ of cases. In addition, for $22 \%$ of the product-configuration experiences, the participants felt the need to interact both inside and outside of the configurator with other OSC users.

\subsubsection{Configurator users' need for social interaction by combining the with-whom and which-step dimensions}

Hereafter, we focus on the results derived by combining the users' need to interact with the different referents (with whom) with the different steps of the configuration/shopping processes (which step). Table 5 shows that the users experienced a considerable need to interact with their contacts and the table depicts in detail when this need was felt to be of importance. In particular, in $48 \%$ of cases, the participants needed to interact with their contacts during the first step when they were collecting information to be guided toward their initial configuration solution.

Table 5 also shows that in $47 \%$ of cases, the OSC users needed to interact with their contacts during the second step-intermediate evaluation-when they felt the need to be advised about the configured product or to be reassured about their choices.

The users' need to interact with their contacts was stronger especially during the final configurationevaluation step (61\%). During this step, interaction with trustworthy individuals is crucial because this is when users evaluate their design solution.

The OSC users' need to interact with experts from the company varied for each configuration step. The participants in our research experienced this need for both the initial idea development $(41 \%)$ and for the final evaluation steps (45\%). However, they experienced this need in a stronger way during the intermediate evaluation stage $(52 \%)$, when configuration is ongoing and when it may be necessary to collect technical information about the product, or information that only experts from the company can provide.

In the smaller group of cases where the OSC users felt the need to interact with other configurator users, the interest in interacting with those referents was almost the same across the various configuration steps. However, it decreases slightly when moving from the initial idea- 
development step (32\%) down to the post-purchasing step (19\%).

Table 5. Experienced need to interact with different actors during different configuration stages

\begin{tabular}{|c|c|c|c|c|c|}
\hline \multirow{2}{*}{$\begin{array}{c}\text { With } \\
\text { whom }\end{array}$} & \multirow{2}{*}{$\begin{array}{c}\text { Scale of } \\
\text { agreement }\end{array}$} & \multicolumn{4}{|c|}{ Configuration/shopping steps } \\
\hline & & \begin{tabular}{|c|}
$\begin{array}{c}\text { Initial idea } \\
\text { devel. }\end{array}$ \\
\end{tabular} & $\begin{array}{c}\text { Interim } \\
\text { Eval. }\end{array}$ & $\begin{array}{l}\text { Final } \\
\text { Eval. }\end{array}$ & $\begin{array}{l}\text { Post- } \\
\text { Purch. }\end{array}$ \\
\hline \multirow{4}{*}{ UXC } & Disagreement & $32 \%$ & $29 \%$ & $19 \%$ & $44 \%$ \\
\hline & Neutral & $20 \%$ & $24 \%$ & $20 \%$ & $24 \%$ \\
\hline & Agreement & $48 \%$ & $47 \%$ & $61 \%$ & $32 \%$ \\
\hline & Total & $100 \%$ & $100 \%$ & $100 \%$ & $100 \%$ \\
\hline & & $\begin{array}{c}\text { Initial idea } \\
\text { devel. }\end{array}$ & $\begin{array}{l}\text { Interim } \\
\text { Eval. }\end{array}$ & $\begin{array}{l}\text { Final } \\
\text { Eval. }\end{array}$ & $\begin{array}{l}\text { Post- } \\
\text { Purch. }\end{array}$ \\
\hline \multirow{4}{*}{ EXP } & Disagreement & $39 \%$ & $28 \%$ & $36 \%$ & $48 \%$ \\
\hline & Neutral & $20 \%$ & $20 \%$ & $20 \%$ & $20 \%$ \\
\hline & Agreement & $41 \%$ & $52 \%$ & $45 \%$ & $31 \%$ \\
\hline & Total & $100 \%$ & $100 \%$ & $100 \%$ & $100 \%$ \\
\hline & & $\begin{array}{c}\text { Initial idea } \\
\text { devel. }\end{array}$ & $\begin{array}{l}\text { Interim } \\
\text { Eval. }\end{array}$ & $\begin{array}{l}\text { Final } \\
\text { Eval. }\end{array}$ & $\begin{array}{l}\text { Post- } \\
\text { Purch. }\end{array}$ \\
\hline \multirow{4}{*}{ OCU } & Disagreement & $47 \%$ & $51 \%$ & $52 \%$ & $61 \%$ \\
\hline & Neutral & $21 \%$ & $23 \%$ & $24 \%$ & $20 \%$ \\
\hline & Agreement & $32 \%$ & $26 \%$ & $24 \%$ & $19 \%$ \\
\hline & Total & $100 \%$ & $100 \%$ & $100 \%$ & $100 \%$ \\
\hline \multicolumn{6}{|c|}{$\begin{array}{l}\text { UXC = users' contacts; EXP = experts from the company; OCU = other } \\
\text { configurator users; Initial idea devel. = initial idea development; Interim } \\
\text { Eval. = intermediate evaluation; Final Eval. = final evaluation; Post- } \\
\text { Purch. = post-purchase; Neutral = neither agree nor disagree }\end{array}$} \\
\hline
\end{tabular}

\section{DISCUSSION}

The results of the present study show that the need for social interaction while shopping online via OSCs is definitely experienced by the OSC users who participated in our study in almost all of the online configuration experiences they underwent. Moreover, the results show that OSC users require this need to be satisfied online in different ways along the specific dimensions that characterize the OSC-SSW connections (i.e. the when, where, with-whom, and which-step dimensions).

Interestingly, from our results, it was found that the OSC users felt the need to interact with different referents during various steps of the configuration process and, depending on the referent with whom they wanted to interact, they looked for different interaction modalities in terms of when and where the interactions were taking place.

Another interesting result emerged from our study about the with-whom dimension, in that during the initial steps of their configuration process, the users felt the need to interact with their contacts and with experts from the company. These results are meaningful because they show, for the first time, who OSC users seek advice from during those specific steps. With respect to receiving feedback during the initial steps of the configuration process, Hildebrand et al. [23] found that receiving feedback from other users of equal or even of high expertise during the initial stage of the self-design process leads to a less unique final configuration solution and less product satisfaction by OSC users with low expertise. The results from our study raise a further question: If low-expertise users were to interact with trustworthy referents who know their personal tastes (such as the users' personal contacts), thus receiving feedback that is more in line with their product preferences, would they end up with a unique configuration solution that satisfies them more?

By exploring the social-interaction needs of OSC users and relating them to the characteristics of OSC-SSW connections, this study extends the previous studies by Blazek et al. [27] and Grosso et al. [28]. By exploring the social-interaction needs of OSC users during the various steps of the configuration process and engaging different referents, this study aligns with previous studies on social-product customization systems [18, 23, 29, 30]. While previous studies on social configuration-systems investigated the interplay between networking of configurator users and configuration systems. The present study extents the analysis of the networking to different actors with whom OSCs users experienced the need to interact with during the shopping process via.

Finally, the present study contributes to research on collaborative online shopping [44, 48, 73, 74] by analyzing the social-interaction needs of customers who shop for customizable products via OSCs.

\subsection{Users' social-interaction need by varying the when, where, and which-step dimensions}

If we compare the results reported in section 4 with the characterization of the OSC-SSW connection modalities provided by Grosso et al. [25], we can see that the wide set of connection modalities singled out by Grosso et al. [25] correspond to the great heterogeneity of socialinteraction needs experienced by the OSC users. Hereafter, we provide more details on this correspondence.

The when dimension. OSC users experienced the need for social interaction both synchronously and asynchronously, even though there was a slightly greater frequency for synchronous interactions.

The connection modalities that enable real-time socialinteraction options are M8, a modality that enables realtime interaction via live chats between configurator users and company representatives, and $\mathrm{M} 2$, a modality that enables sharing different information about the configurator and the configuration solution developed by users. Conversely, the connection modalities that enable no real-time social-interaction options are M7, M6 and, M5. M7 is a two-pronged modality that sends e-mails directly to a user's contacts (M7.1) or to a company representative (M7.2). M6 is a modality that brings configurator users to the company's forum web page, M5, comprising two modalities of a blog diary and blog posts that bring configurator users to the company blog website, where configurator users can explore messages left by company representatives or other customers.

The where dimension. OSC users experienced the need for social interaction both inside and outside of the configuration environment. OSC users felt the need to engage in interactions with real people in both environments (inside/outside).

The connection modalities that enable social-interaction options inside the environment are M8, a modality that enables a live chat between users and company representatives, and $\mathrm{M} 2$, a modality with three variants that enable users to share configurator links (M2.1), the 
intermediate configuration solution (M2.3) or the final one (M2.2). The OSC-SSW connection modalities that support users in interacting with others outside of the configuration environment are all of the modalities that bring users from the configuration environment to online social platforms outside the configurator. M5.2 is a blogpost modality that brings users to the company blog website where they can read and evaluate comments left by other customers, and M6 is a forum modality where users can interact with other customers as people with the same interests.

The which-step dimension. As recalled from the paper's introduction, Franke et al. [18] suggested that, for configurators, a promising method of providing feedback would be to include a function that allows users to submit their interim design solutions for them to obtain rapid social feedback from other users who are online. Their suggestion is focused on the intermediate stage of configuration and presumes that OSCs users need such feedback. Recent studies investigated the social comparison and feedback between OSCs users at different steps of their configuration process [23, 26, 27]. Our results not only show that OSC users experienced the need for social interaction during each step of their shopping process via online sales configurators but also include the post-purchase step when the configured product has been purchased. A slightly greater OSCuser need is noted for digital interactions with real people during the final stage of configuration evaluation. Hereafter, we provide details on the correspondence between each configuration/shopping step and the OSC-SSW connection modalities currently active in commercial OSCs.

Idea-development step. The connection modalities that support users during the idea-development step are M1, M5, M6, and M8. The M5 and M6 modalities connect each one to an interaction environment outside of the configurator. M5, a two-pronged modality consisting of a blog diary and blog, connects users with company blogs, and $\mathrm{M} 6$ connects them to company forums, where users can collect information that has been updated by the company and/or other customers. The M8 modality is a live chat between users and company representatives to provide outlines of technical information on products and/or the configurator. M1 is a modality that connects users with a company's social network profile where they can look for ideas.

Intermediate configuration. During this configurationevaluation step, users can be supported in their interactions with real people by the same modalities mentioned above. Specifically, M5 and M6 are the modalities that support users in interacting both with company experts and other consumers, while M8 only allows interactions with company representatives, and M2.1 supports users in sharing the link to the configurator on their social profiles. Finally, M2.3 supports users in interacting with their contacts during the intermediate stage by sharing a partial configuration solution on their social network profiles.

The abovementioned connection modalities support OSC users in interacting with different referents whenever they look for them. In particular, M2.3 supports
OSC users in receiving feedback from their personal contacts as trustworthy people who know the users' personal tastes and preferences. M2.3 could help in overcoming the negative influence that the feedback provided by other OSC users can have on inexpert configurator users. As stated by Hildebrand et al. [23], feedback provided by other users during the initial steps of self-design processes pushes low-expertise users toward choosing final configuration solutions that do not satisfy them. In more detail, feedback provided during the initial steps of the configuration process from peers with equal or even higher expertise stifles the uniqueness of the final solution configured by inexpert OSC users. As a result, the reduced uniqueness of their configurations leads to reduced levels of customer satisfaction [23].

Final evaluation step. During the users' final evaluation, in addition to the abovementioned modalities (M5, M6, M8), the modalities that can support users in interacting with real people include M2.2, which enables sharing a final configuration solution selected by a user on his or her social network profile. M7.1 supports users during this final stage by sending an e-mail to the users' contacts with the final, selected configuration. During the post-purchase stage, users can interact with company representatives, supported by $\mathrm{M} 1, \mathrm{M} 5$, and M6. M5 and M6 also enable interaction among users and other configurator users.

Post-purchase step. During this shopping step, customers evaluate their purchase experience and look for social rewards; additionally, customers look for interactions with real people in order to be reassured about their purchases and/or to reduce any eventual post-decisional regret. The connection modalities that can support users in social interactions are M1, where users can connect to company social network profiles and leave comments or posts about their purchases, as well as users being able to post their comments or review both their experiences and configured products supported by M5.2 and M6. M7 allows users to send emails to the company for any type of communication following their purchase.

\subsection{Users' social-interaction need by varying the with-whom dimension}

Research on collaborative online shopping calls for the use of research approaches that include social and relational theoretical backgrounds $[44,48,74]$.

Kim et al. [73] adopted the social and relational perspective to investigate how to enhance shoppers' experiences by implementing web shops with features designed to support shoppers during collaborative online shopping: "Collaborative online shopping refers to an activity in which a consumer shops at an e-commerce website with remotely located shopping partners such as friends or family" [73], p.169].

Previous research on product customization has focused on the importance of the users' community to improve customers' self-design, and posited the important role of peer communities in influencing (both positively and negatively) consumers' decision making $[18,31]$. The present study takes a step forward with respect to those 
studies by considering different types of actors involved in social interactions. In particular, the present study analyzed OSC users' need to interact with various referents such as the users' contacts, company representatives, and other customers. Moreover, it deepened this analysis by exploring the when, the where, and the which-step dimensions of interaction need for each type of referent (with whom). These dimensions are analyzed for the very first time.

OSC users experienced the need to interact not with an "unknown" someone, but with specific referents. They felt the need for interaction with their contacts and company representatives, with a slightly greater emphasis on the former, while the need to interact with other configurator users was perceived as less relevant. Hereafter, we provide details on the OSC-SSW connection modalities that support OSC users in interacting with each referent type.

Users' contacts. The connection modalities that support users in interacting with their contacts are M2, comprising the three modalities of content sharing via the users' social networks, and M7.1 (e-mailing the users' final configurations to friends).

Experts from the company. Interactions with company representatives are enabled by M1 (links to the company's social network profiles), M5.2 (the company's blog posts), M6 (the company's forums), M7.2 (the company's e-mail), and M8 (live chats with the company's representatives).

Other configurator users. The M1, M5.2, and M6 modalities support users in interacting with other customers who have previously used the same configurator. Each modality allows users to post comments on different environments such as the company's blogs, forums, and social network sites, where posts can also be read and replied to by other customers.

Depending on the referent with whom users need to interact with, they look for interaction modalities that are different in terms of where, when, and during which step those interactions take place along the configuration/shopping process, as detailed hereafter.

The when dimension. OSC users look for interaction with experts from the company and with their own contacts in real time, with a slightly greater preference for real-time interactions with the users' contacts. M.8 (live chats) supports users in real-time interactions with experts from the company, while M2.3 can support users in interacting with their own contacts in real time. M2 (comprising three modalities of content sharing via users' social network profiles) enables interactions between users and their contacts but it is not guaranteed that those interactions will occur in real time because it depends on whether the users' contacts are available and connected to the same social network profiles when the OSC users are configuring their products. It is interesting to note that, up to now, none of the identified connection modalities guarantee supporting users in interacting in real time with their contacts while configuration is ongoing.

The where dimension. Users prefer interactions with their contacts to occur outside instead of inside of the configuration environment. In contrast, users prefer interactions with experts to occur inside of the configuration environment. The respondents who felt the need to interact with other OSC users did not have a clear preference regarding where the interaction should take place. The connection modalities that support users in interacting with their contacts outside of the configuration environment are M.2 (comprising three modalities of content sharing via the users' social network profiles) and M.7.1 (e-mailing the users' final configurations to friends), while M8 enables a live chat between experts from the company and OSC users.

The which-step dimension. OSC users experienced the need to interact with real people during each step of the configuration/shopping process but this need was greater for the intermediate configuration-evaluation (step 2) and the final configuration-evaluation (step 3). More precisely, OSC users felt more need to interact with experts from the company during the step 2, while they felt more need to interact with their contacts during the step 3. The connection modality that supports users in interacting during step 2 with experts from the company is M8, while the connection modality that supports users in interacting with their contacts during step 3 is M2.3, which enables the sharing of the final configuration via the users' social network platforms where the users can interact with their contacts.

Table 6 reports on an overview of the results achieved in the present study combined with the main characteristics of the OSC-SSW connection modalities currently active in OSCs.

Table 6. Result overview and social-interaction options enabled by the social software

\begin{tabular}{|c|c|c|c|c|c|c|c|c|c|c|c|}
\hline \multirow{3}{*}{$\begin{array}{l}\text { Need for } \\
\text { social } \\
\text { interaction }\end{array}$} & \multicolumn{11}{|c|}{ Perceived social-interaction needs by dimension } \\
\hline & \multicolumn{4}{|c|}{ Which step } & \multicolumn{3}{|c|}{ With whom } & \multicolumn{2}{|c|}{ When } & \multicolumn{2}{|c|}{ Where } \\
\hline & 1 & 2 & 3 & 4 & EXP & $\mathrm{UXC}$ & $\mathrm{OCU}$ & RT & NRT & In & Out \\
\hline $\begin{array}{r}\text { Not } \\
\text { perceived }\end{array}$ & $17 \%$ & $13 \%$ & $11 \%$ & $25 \%$ & $17 \%$ & $10 \%$ & $31 \%$ & $9 \%$ & $13 \%$ & $11 \%$ & $8 \%$ \\
\hline Neutral & $16 \%$ & $18 \%$ & $15 \%$ & $24 \%$ & $15 \%$ & $15 \%$ & $24 \%$ & $9 \%$ & $18 \%$ & $12 \%$ & $14 \%$ \\
\hline Perceived & $66 \%$ & $69 \%$ & $74 \%$ & $52 \%$ & $68 \%$ & $75 \%$ & $46 \%$ & $83 \%$ & $68 \%$ & $76 \%$ & $78 \%$ \\
\hline Total & $\begin{array}{c}100 \\
\%\end{array}$ & $\begin{array}{c}100 \\
\%\end{array}$ & $\begin{array}{c}100 \\
\%\end{array}$ & $\begin{array}{c}100 \\
\%\end{array}$ & $\begin{array}{c}100 \\
\%\end{array}$ & $\begin{array}{c}100 \\
\%\end{array}$ & $\begin{array}{c}100 \\
\%\end{array}$ & $\begin{array}{c}100 \\
\%\end{array}$ & $\begin{array}{c}100 \\
\%\end{array}$ & $\begin{array}{c}100 \\
\%\end{array}$ & $\begin{array}{c}100 \\
\%\end{array}$ \\
\hline $\begin{array}{c}\text { Connection } \\
\text { modality }\end{array}$ & \multicolumn{11}{|c|}{ Social-interaction need supported by the modality } \\
\hline \multicolumn{12}{|c|}{ Characterization of co-located-based connection modalities } \\
\hline M.1 & $\mathrm{X}$ & $\mathrm{X}$ & & $\mathrm{X}$ & & & & & $\mathrm{X}$ & & $\mathrm{X}$ \\
\hline M.5.1 & $\mathrm{X}$ & & & & & & & & $\mathrm{X}$ & & $\mathrm{X}$ \\
\hline M.5.2 & $\mathrm{X}$ & $\mathrm{X}$ & $\mathrm{X}$ & $\mathrm{X}$ & $\mathrm{X}$ & & $\mathrm{X}$ & & $\mathrm{X}$ & & $\mathrm{X}$ \\
\hline M.6 & $\mathrm{X}$ & $\mathrm{X}$ & $\mathrm{X}$ & $\mathrm{X}$ & $\mathrm{X}$ & & $\mathrm{X}$ & & $\mathrm{X}$ & & $\mathrm{X}$ \\
\hline M.7.2 & $\mathrm{X}$ & $\mathrm{X}$ & $\mathrm{X}$ & $\mathrm{X}$ & $\mathrm{X}$ & & & & $\mathrm{X}$ & & $\mathrm{X}$ \\
\hline \multicolumn{12}{|c|}{ Characterization of integration-based connection modalities } \\
\hline M2.1 & $\mathrm{X}$ & & & & & $\mathrm{X}$ & & $\mathrm{X}$ & & & $\mathrm{X}$ \\
\hline M2.2 & & & $\mathrm{X}$ & & & $x$ & & $x$ & & & $X$ \\
\hline M2.3 & & $X$ & $x$ & & & $x$ & & $x$ & & & $X$ \\
\hline M3 & $X$ & $X$ & & & & $X$ & & & & & \\
\hline M4 & $x$ & & & & $x$ & $x$ & $x$ & $x$ & & $x$ & \\
\hline M7.1 & & & $X$ & & & $x$ & & & & $x$ & \\
\hline M8 & $X$ & $X$ & $x$ & $x$ & $X$ & & & $X$ & & $X$ & \\
\hline
\end{tabular}

Social-interaction characteristics. With whom: EXP = experts from the company; $U X C=$ online contacts; $O C U=$ other configurator users or customers. When: $R T=$ in real time; NRT = not in real time. Where: In = inside of the configuration environment; Out = outside; Which step: $1=$ initial idea development; 2 = intermediate evaluation; 3 = configuration evaluation; 4 = post-purchase. Neutral = neither agree nor disagree

Source: The bottom part has been adapted from Grosso et al. [25]. 
Table 6 is structured as follows: Column 1, in the upper part, reports on the scale of agreement, and in the lower part, the list of connection modalities between the OSC and the SSW is given. Columns $2-5$ show the stages of the configuration/sopping process: The upper part reports on the percentage of users' experienced need for social interaction and the bottom part reports a mark (X) wherever each connection modality is active along the configuration/shopping process. For columns 6-12, the upper part reports on the percentage of users' experienced need for social interaction and the lower part shows a mark (X) to highlight the correspondence of the characteristics of social interaction enabled by each connection modality (i.e. with whom, where, when, and which step).

\section{CONCLUSIONS}

The present study first assessed the extent of the OSC users' need to digitally interact with real people while shopping via OSCs. Subsequently, it detected which interaction characteristics OSC users are looking for. Finally, it compared the obtained results about the OSC users' need for interaction and the social interactions enabled by the OSC-SSW connection modalities currently active in OSCs.

The results of this exploratory study show that the need to interact online with real people is definitely experienced by online shoppers while using OSCs. Moreover, it was found that OSC users require this need to be satisfied online in different ways along the specific dimensions that characterize the connections between OSCs and the SSW. Finally, it showed that most interaction needs experienced by OSC users can be satisfied by currently available OSCSSW connections. Even though, there are no connections that are able to support OSC users in interacting with their contacts in real time either inside or outside of the configuration environment when OSC users looks for this modality. For example, there are still missing connections between OSCs and the SSW that support configurator users in interacting with their contacts in real time inside of the configuration environment or outside of the configuration environment by guaranteeing, also in this case, the synchronicity of the interaction with their contacts. These results move one step further the research on the connection between OSCS and the SSW [28] by describing all of the OSC-SSW connection modalities through the lens of consumer-socialization theory. The present work complements the line of enquiry on socially enriched configuration environment by showing whether and how the currently available OSC-SSW connection modalities satisfy the social-interaction needs experienced by OSC users while shopping online, thus contributing to the evaluation of the effectiveness of such connections. However, this line of investigation is still missing an important piece; namely, an explanation of the motivations that lead OSC users to experience the socialinteraction need they perceive as relevant while shopping via OSCs. The present work has provided some initial points on this aspect; however, an ad hoc study would be welcome to systematically examine this issue further. Our results also support the need for further investigations on social-product customization systems and in particular on the configuration process as a group-decision process. The contribution of the present work is to analyze OSC users need to interact with different referents at different steps of the configuration/shopping process. By showing that the OSC users need to interact with different referents while configuring their products or services, our study also supports the importance of studying the configuration process as a social process [18, 31, 73, 75]. Knowledge about the configuration process as a group-decision process [76], and about the need for the digital interaction between OSC users with different referents could be new knowledge that needs to be considered and even modeled in configuration environments, thus further increasing the knowledge-management aspect of configurators [77]. Furthermore, this knowledge-related aspect could present new challenges for the implementation of OSCs, in addition to those already known [78] and peculiar to business-toconsumer contexts [79].

Finally, our study suggests the possibility of improving OSCs by not only working on the established OSC capabilities (see [80] as an example of improvement identification), but also working on the OSC's connection with SSW, thus satisfying the users' social-interaction needs during their configuration processes. We know that these OSC capabilities positively influence both experience [7, 15] and product-related customization [2, $57,61]$. It would be interesting to explore whether by acting on OSC-SSW connections, it could be possible to increase the OSC capabilities or their effect on customization benefits.

For practitioners, the most important results of this study relate to the multiplicity of OSC-SSW connection modalities adopted by single OSCs. The heterogeneity of the need for social interactions that emerged from the OSC use experiences we analyzed constitutes an explanation of why many OSCs are connected to SSW in a multiplicity of modalities [28]. Consequently, mass customizers that implement OSCs should carefully consider the multiplicity of the social-interaction needs of their target customers along the dimensions we have considered in our study. In this way, they can choose a set of OSC-SSW connections that altogether best satisfy these interaction needs. Unfortunately, providing implementation guidelines of OSC-SSW connections was not within the scope of the present work. Future studies should look at this issue and place the answer in the wider context of socially enriched mass customization implementation guidelines $[63,81]$ considering the viability for small and medium enterprises too [63, 81, 82].

The main limitation of this study concerns the results on the post-purchase step. This is because we asked the participants to answer by imagining that they had actually bought a final configuration that they had chosen. Therefore, while the participants really passed through all the other configuration-shopping steps, they only figured out this step in their mind. Thus, the information regarding this step of the shopping process should be considered as less indicative compared with the information provided for the other steps. Notwithstanding this limitation, we decided to include this information to provide at least some preliminary evidence that could be useful in terms of designing better future studies. 


\section{REFERENCES}

[1] Trentin, A., Perin, E. and Forza, C. (2013), "Sales configurator capabilities to avoid the product variety paradox: Construct development and validation", Computers in Industry, Vol. 64, No. 4, pp. 436-447.

[2] Sandrin, E., Trentin, A., Grosso, C. and Forza, C. (2017) "Enhancing the consumer-perceived benefits of a masscustomized product through its online sales configurator: An empirical examination", Industrial Management \& Data Systems, Vol. 117, No. 6, pp. 1295-1315.

[3] Forza, C. and Salvador, F. (2006), Product information management for mass customization: connecting customer, frontoffice and back-office for fast and efficient customization, Springer.

[4] Huang, Z. and Benyoucef, M. (2013), "From e-commerce to social commerce: A close look at design features", Electronic Commerce Research and Applications, Vol. 12, No. 4, pp. 246-259.

[5] Huang, Z. and Benyoucef, M. (2015), "User preferences of social features on social commerce websites: An empirical study", Technological Forecasting and Social Change, Vol. 95, pp. 57-72.

[6] Warr, W.A. (2008), "Social software: fun and games, or business tools?", Journal of Information Science, Vol. 34, No. 4, pp. 591604.

[7] Wang, X., Yu, C. and Wei, Y. (2012), "Social media peer communication and impacts on purchase intentions: $A$ consumer socialisation framework", Journal of Interactive Marketing, Vol. 26, No. 4, pp. 198-208.

[8] Matt, C., Hess, T. and Benlian, A. (2015), "Digital transformation strategies", Business \& Information Systems Engineering, Vol. 57, No. 5, pp. 339-343.

[9] Fitzgerald, M., Kruschwitz, N., Bonnet, D. and Welch, M. (2014), "Embracing digital technology: a new strategic imperative", MIT Sloan Management Review, Vol. 55, No. 2, p. 1.

[10] Sashi, C. (2012), "Customer engagement, buyer-seller relationships, and social media", Management Decision, Vol. 50, No. 2, pp. 253-272.

[11] Kane, G.C.J., Palmer, D., Phillips, A.N., Kiron, D. and Buckley, N. (2014), "Moving beyond marketing: Generating social business value across the enterprise", MIT Sloan Management Review, Vol. 56 , No. 1 , p. 1.

[12] Boyd, D.M. and Ellison, N.B. (2007), "Social network sites: Definition, history, and scholarship", Journal of ComputerMediated Communication, Vol. 13, No. 1, pp. 210-230.

[13] Aral, S., Dellarocas, C. and Godes, D. (2013), "Introduction to the special issue-social media and business transformation: a framework for research", Information Systems Research, Vol. 24, No. 1, pp. 3-13.

[14] Bingham, T. and Conner, M. (2010), The new social learning: A guide to transforming organizations through social media, BerrettKoehler Publishers.

[15] Aichner, T. and Jacob, F. (2015), "Measuring the degree of corporate social media use", International Journal of Market Research, Vol. 57, No. 2, pp. 257-276.

[16] Schoenherr, T. (2015), "The power of social media in supply management", Inside Supply Management, Vol. 26, No. 6, pp. 10-11.

[17] Piller, F., Vossen, A and Ihl, C. (2011), "From social media to social product development: the impact of social media on cocreation of innovation", Die Unternehmung-Swiss Journal of Business Research and Practice, Vol. 66, No. 1, pp. 7-27.

[18] Franke, N., Keinz, P. and Schreier, M. (2008), "Complementing mass customization toolkits with user communities: How peer input improves customer self-design", Journal of Product Innovation Management, Vol. 25, No. 6, pp. 546-559.

[19] Khoury, M., Shen, X. and Shirmohammadi, S. (2007), "A peer-topeer collaborative virtual environment for E-commerce", in, Proceedings of the Electrical and Computer Engineering Conference, IEEE, pp. 828-831.

[20] Lecinski, J. (2012), Winning the Zero Moment of Truth, Google Inc., Mountain View, CA, USA.

[21] Kaplan, A.M. and Haenlein, M. (2010), "Users of the world, unite! The challenges and opportunities of Social Media", Business Horizons, Vol. 53, No. 1, pp. 59-68.

[22] Aichner, T. and Perkmann, U. (2013), "Social media:: Opportunities and risks for regional market research", International Journal of Market Research, Vol. 55, No. 5, pp. 609-610.

[23] Hildebrand, C., Häubl, G., Herrmann, A. and Landwehr, J.R. (2013), "When social media can be bad for you: Community feedback stifles consumer creativity and reduces satisfaction with self-designed products", Information Systems Research, Vol. 24, No. 1, pp. 14-29.

[24] Squire, B., Brown, S., Readman, J. and Bessant, J. (2006), "The impact of mass customisation on canufacturing trade-offs", Production and Operations Management, Vol. 15, No. 1, pp. 10-21.

[25] Pine, B.J. (1993), Mass customization: the new frontier in business competition, Harvard Business Press, Boston, MA, USA.

[26] Liu, G., Shah, R. and Schroeder, R.G. (2006), "Linking work design to mass customization: a sociotechnical systems perspective", Decision Sciences, Vol. 37, No. 4, pp. 519-545.

[27] Blazek, P., Kolb, M., Partl, M. and Streichsbier, C. (2012), "The usage of social media applications in product configurators", International Journal of Industrial Engineering and Management (IJIEM), Vol. 3, No. 4, pp. 179-183.

[28] Grosso, C., Forza, C. and Trentin, A. (2017), "Supporting the social dimension of shopping for personalized products through online sales configurators", Journal of Intelligent Information Systems, Vol. 49, No. 1, pp. 9-35.

[29] Schlager, T., Hildebrand, C., Häubl, G., Franke, N. and Herrmann, A. (2018), "Social product-customization systems: Peer input, conformity, and consumers' evaluation of customized products", Journal of Management Information Systems, Vol. 35, No. 1, pp. 319-349.

[30] Moreau, C.P. and Herd, K.B. (2009), "To each his own? How comparisons with others influence consumers' evaluations of their self-designed products", Journal of Consumer Research, Vol. 36, No. 5 , pp. 806-819.

[31] Jeppesen, L.B. (2005), "User toolkits for innovation: Consumers support each other", Journal of Product Innovation Management, Vol. 22, No. 4, pp. 347-362.

[32] Roy Dholakia, R. (1999), "Going shopping: key determinants of shopping behaviors and motivations", International Journal of Retail \& Distribution Management, Vol. 27, No. 4, pp. 154-165.

[33] Lueg, J.E. and Finney, R.Z. (2007), "Interpersonal communication in the consumer socialization process: scale development and validation", Journal of Marketing Theory and Practice, Vol. 15, No. 1, pp. 25-39.

[34] Moschis, G.P. and Churchill Jr, G.A. (1978), "Consumer socialization: A theoretical and empirical analysis", Journal of Marketing Research, Vol. 15, No. 4, pp. 599-609.

[35] Ward, S. (1974), "Consumer socialization", Journal of Consumer Research, Vol. 1, No. 2, pp. 1-14.

[36] Ward, S., Klees, D.M. and Robertson, T.S. (1987), "Consumer socialization in different settings: An international perspective", Advances in Consumer Research, Vol. 14, No. 1, pp. 468-472.

[37] Hennig-Thurau, T., Malthouse, E.C., Friege, C., Gensler, S., Lobschat, L., Rangaswamy, A. and Skiera, B. (2010), "The impact of new media on customer relationships", Journal of Service Research, Vol. 13, No. 3, pp. 311-330.

[38] Ward, S. (1978), "Contributions of socialization theory to consumer behavior research", American Behavioral Scientist, Vol. 21, No. 4, pp. 501-514.

[39] Chevalier, J.A. and Mayzlin, D. (2006), "The effect of word of mouth on sales: Online book reviews", Journal of Marketing Research, Vol. 43, No. 3, pp. 345-354.

[40] Trusov, M., Bucklin, R.E. and Pauwels, K. (2009), "Effects of word-of-mouth versus traditional marketing: findings from an internet social networking site", Journal of Marketing, Vol. 73, No. 5, pp. 90-102.

[41] Zhang, J. and Daugherty, T. (2009), "Third-person effect and social networking: implications for online marketing and word-ofmouth communication", American Journal of Business, Vol. 24, No. 2, pp. 53-64.

[42] Bandura, A. and Walters, R.H. (1977), Social learning theory, Prentice-hall Englewood Cliffs, NJ.

[43] Bearden, W.O. and Etzel, M.J. (1982), "Reference group influence on product and brand purchase decisions", Journal of Consumer Research, Vol. 9, No. 2, pp. 183-194.

[44] Chen, A., Lu, Y. and Wang, B. (2017), "Customers' purchase decision-making process in social commerce: A social learning perspective", International Journal of Information Management, Vol. 37, No. 6, pp. 627-638.

[45] Bikhchandani, S., Hirshleifer, D. and Welch, I. (1998), "Learning from the behavior of others: Conformity, fads, and informational cascades", Journal of Economic Perspectives, Vol. 12, No. 3, pp. $151-170$. 
[46] Gao, Q., Dai, Y., Fan, Z. and Kang, R. (2010), "Understanding factors affecting perceived sociability of social software", Computers in Human Behavior, Vol. 26, No. 6, pp. 1846-1861.

[47] Shin, D.-H. (2013), "User experience in social commerce: in friends we trust", Behaviour \& Information Technology, Vol. 32, No. 1, pp. 52-67.

[48] Wang, Y. and Yu, C. (2017), "Social interaction-based consumer decision-making model in social commerce: The role of word of mouth and observational learning", International Journal of Information Management, Vol. 37, No. 3, pp. 179-189.

[49] Gershoff, A.D. and Johar, G.V. (2006), "Do you know me? Consumer calibration of friends' knowledge", Journal of Consumer Research, Vol. 32, No. 4, pp. 496-503.

[50] Wang, X., Yu, C. and Wei, Y. (2012), "Social media peer communication and impacts on purchase intentions: A consumer socialization framework", Journal of Interactive Marketing, Vol. 26, No. 4, pp. 198-208.

[51] Mandl, M., Felfernig, A., Teppan, E. and Schubert, M. (2011), "Consumer decision making in knowledge-based recommendation", Journal of Intelligent Information Systems, Vol. 37, No. 1, pp. 1-22.

[52] Tufekci, Z. (2008), "Can you see me now? Audience and disclosure regulation in online social network sites", Bulletin of Science, Technology \& Society, Vol. 28, No. 1, pp. 20-36.

[53] Falkner, A., Felfernig, A. and Haag, A. (2011), "Recommendation technologies for configurable products", Ai Magazine, Vol. 32, No. 3, pp. 99-108.

[54] Heiskala, M. (2007), "Mass customization with configurable products and configurators: a review of benefits and challenges", in, Mass customization information systems in business, Igi Global, pp. 1-32.

[55] Tiihonen, J. and Felfernig, A. (2010), "Towards recommending configurable offerings", International Journal of Mass Customisation, Vol. 3, No. 4, pp. 389-406.

[56] Tiihonen, J. and Felfernig, A. (2017), "An introduction to personalization and mass customization", Journal of Intelligent Information Systems, Vol. 49, No. 1, pp. 1-7.

[57] Trentin, A., Perin, E. and Forza, C. (2014), "Increasing the consumer-perceived benefits of a mass-customization experience through sales-configurator capabilities", Computers in Industry, Vol. 65, No. 4, pp. 693-705.

[58] Merle, A., Chandon, J.L., Roux, E. and Alizon, F. (2010), "Perceived value of the mass-customized product and mass customization experience for individual consumers", Production and Operations Management, Vol. 19, No. 5, pp. 503-514.

[59] Franke, N., Schreier, M. and Kaiser, U. (2010), "The "I designed it myself" effect in mass customization", Management Science, Vol. 56, No. 1, pp. 125-140.

[60] Franke, N. and Schreier, M. (2008), "Product uniqueness as a driver of customer utility in mass customization", Marketing Letters, Vol. 19, No. 2, pp. 93-107.

[61] Sandrin, E. (2017), "Synergic effects of sales-configurator capabilities on consumer-perceived benefits of mass-customized products", International Journal of Industrial Engineering and Management, Vol. 8, No. 3, pp. 177-188.

[62] Kristjansdottir, K., Shafiee, S., Hvam, L., Bonev, M. and Myrodia, A. (2018), "Return on investment from the use of product configuration systems-A case study", Computers in Industry, Vol. 100, pp. 57-69.

[63] Suzić, N., Forza, C., Trentin, A. and Anišić, Z. (2018), "Implementation guidelines for mass customization: current characteristics and suggestions for improvement", Production Planning \& Control, Vol. 29, No. 10, pp. 856-871.

[64] Franke, N. and Hader, C. (2014), "Mass or only "niche customization"? Why we should interpret configuration toolkits as learning instruments", Journal of Product Innovation Management, Vol. 31, No. 6, pp. 1214-1234.

[65] Flanagin, A.J. and Metzger, M.J. (2013), "Trusting expert-versus user-generated ratings online: The role of information volume, valence, and consumer characteristics", Computers in Human Behavior, Vol. 29, No. 4, pp. 1626-1634.

[66] Blackwell, R.D., Miniard, P.W. and Engel, J.F. (2001), Consumer behavior 9th, Mason, $\mathrm{OH}$.

[67] Solomon, M., Russell-Bennett, R. and Previte, J. (2012), Consumer behaviour, Pearson Higher Education AU.

[68] Franke, N. and Schreier, M. (2010), "Why customers value selfdesigned products: The importance of process effort and enjoyment", Journal of Product Innovation Management, Vol. 27, No. 7, pp. 1020-1031.

[69] Robinson, T., Callahan, C., Boyle, K., Rivera, E. and Cho, J.K. (2017), "I FB: A Q-Methodology Analysis of Why People 'Like'Facebook", International Journal of Virtual Communities and Social Networking, Vol. 9, No. 2, pp. 46-61.

[70] Jenkins, J. (2009), "English as a lingua franca: Interpretations and attitudes", World Englishes, Vol. 28, No. 2, pp. 200-207.

[71] De Swaan, A. (2013), Words of the world: The global language system, John Wiley \& Sons.

[72] Salvador, F. and Forza, C. (2004), "Configuring products to address the customization-responsiveness squeeze: $A$ survey of management issues and opportunities", International Journal of Production Economics, Vol. 91, No. 3, pp. 273-291.

[73] Kim, H., Suh, K.-S. and Lee, U.-K. (2013), "Effects of collaborative online shopping on shopping experience through social and relational perspectives", Information \& Management, Vol. 50, No. 4, pp. 169-180.

[74] Yahia, I.B., Al-Neama, N. and Kerbache, L. (2018), "Investigating the drivers for social commerce in social media platforms: Importance of trust, social support and the platform perceived usage", Journal of Retailing and Consumer Services, Vol. 41, pp. 11-19.

[75] Jeppesen, L.B. and Molin, M.J. (2003), "Consumers as codevelopers: Learning and innovation outside the firm", Technology Analysis \& Strategic Management, Vol. 15, No. 3, pp. 363-383.

[76] Felfernig, A., Boratto, L., Stettinger, M. and Tkalčič, M. (2018), Group recommender systems: An introduction, Springer, Cham, Switzerland.

[77] Shafiee, S., Kristjansdottir, K., Hvam, L. and Forza, C. (2018), "How to scope configuration projects and manage the knowledge they require", Journal of Knowledge Management, Vol. 22, No. 5, pp. 982-1014.

[78] Kristjansdottir, K., Shafiee, S., Hvam, L., Forza, C. and Mortensen, N.H. (2018), "The main challenges for manufacturing companies in implementing and utilizing configurators", Computers in Industry, Vol. 100, pp. 196-211.

[79] Haug, A., Shafiee, S. and Hvam, L. (2019), "The causes of product configuration project failure", Computers in Industry, Vol. 108, pp. 121-131.

[80] Sandrin, E., Forza, C., Anišić, Z., Suzic, N., Grosso, C., Aichner, T. and Trentin, A (2017), "Shoe configurators: a comparative analysis of capabilities and benefits", in: V. Modrak (Ed.), Mass customized manufacturing: theoretical concepts and practical approaches, CRC Press, Taylor \& Francis Group, Boca Raton, FL, pp. 193-216.

[81] Suzić, N., Sandrin, E., Suzić, S., Forza, C., Trentin, A. and Anišić, Z. (2018), "Implementation Guidelines for Mass Customization: A Researcher-Oriented View", International Journal of Industrial Engineering and Management, Vol. 9, No. 4, pp. 229-243.

[82] Stojanova, T., Suzic, N. and Orcik, A. (2012), "Implementation of mass customization tools in small and medium enterprises", International Journal of Industrial Engineering and Management, Vol. 3, No. 4, pp. 253-260. 